\title{
High energy photon reference for radiation protection: tech- nical design of the LINAC beam and ionization chambers; and calculation of monoenergetic conversion coefficients
}

\author{
D. Dusciac a, J.-M. Bordy, J. Daures, V. Blideanu \\ CEA, LIST, Laboratoire National Henri Becquerel (LNE-LNHB), Bât. 602 PC111, CEA-Saclay 91191 Gif-sur-Yvette \\ Cedex, France
}

\begin{abstract}
In this work, we present the results of the first part of a research project aimed at offering a complete response to dosimeters providers and nuclear physicists' demands for high-energy (6 - $9 \mathrm{MeV}$ ) photon beams for radiation protection purposes. Classical facilities allowing the production of high-energy photonic radiation (proton accelerators, nuclear reactors) are very rare and need large investment for development and use. A novel solution is proposed, consisting in the use of a medical linear accelerator, allowing a significant decrease of all costs.Using Monte Carlo simulations (MCNP5 and PENELOPE codes), a specifically designed electron-photon conversion target allowing for obtaining a high energy photon beam (with an average energy weighted by fluence of about $6 \mathrm{MeV}$ ) has been built for radiation protection purposes. Due to the specific design of the target, this "realistic" radiation protection high-energy photon beam presents a uniform distribution of air kerma rate at a distance of $1 \mathrm{~m}$, over a $30 \times 30 \mathrm{~cm}^{2}$ surface. Two graphite cavity ionizing chambers for ionometric measurements have been built. For one of these chambers, the charge collection volume has been measured allowing for its use as a primary standard. The second ionizing chamber is used as a transfer standard; as such it has been calibrated in a 60Co beam, and in the high energy photon beam for radiation protection.The measurements with these ionizing chambers allowed for an evaluation of the air kerma rate in the LINAC based highenergy photon beam for radiation protection: the values cover a range between $36 \mathrm{mGy} / \mathrm{h}$ and $210 \mathrm{mGy} / \mathrm{h}$, compatible with radiation protection purposes.Finally, using Monte Carlo simulations, conversion coefficients from air kerma to dose equivalent quantities have been calculated in the range between $10 \mathrm{keV}$ and $22.4 \mathrm{MeV}$, for the spectral distribution of the fluence corresponding to the beam produced by the linear accelerator of the LNE-LNHB.
\end{abstract}

Cette étude propose une solution pour répondre à la demande des fabricants de dosimètres et des exploitants du nucléaire de disposer de champs de rayonnements photoniques de haute énergie (6 à $9 \mathrm{MeV}$ ) afin de caractériser (test de type) des dosimètres en vue de leur mise sur le marché et de les étalonner. Les installations de production de champs de rayonnements photoniques de haute énergie sont "lourdes » et très rares (accélérateur de protons, réacteurs nucléaires type piles piscines, ...). L'utilisation d'un accélérateur médical permet de mutualiser l'utilisation entre radioprotection et radiothérapie en diminuant les coûts d'exploitation. Dans un premier temps, nous avons défini (par simulations Monte Carlo) puis réalisé un ensemble cible de conversion-atténuateur-égalisateur, qui permet d'obtenir un faisceau homogène de photons de haute énergie (énergie moyenne pondérée par la fluence égale à 6,17 MeV) pour la radioprotection à partir d'un faisceau d'électrons

\footnotetext{
a dorin.dusciac@cea.fr
} 
de $18 \mathrm{MeV}$, fourni par l'accélérateur linéaire médical du LNE-LNHB. Le faisceau ainsi obtenu est homogène en termes de kerma dans l'air sur une surface de $30 \times 30 \mathrm{~cm}^{2}$ à $1 \mathrm{~m}$. Dans un second temps, nous avons fabriqué, assemblé et caractérisé deux chambres d'ionisation à cavité en graphite pour réaliser les mesures ionométriques. Pour l'une de ces chambres, nous avons mesuré le volume de collection des charges permettant ainsi de l'utiliser en tant qu'étalon primaire, l'autre chambre d'ionisation étant un étalon de transfert, elle a été étalonnée dans un faisceau de ${ }^{60} \mathrm{Co}$ et dans le faisceau de photons de haute énergie pour la radioprotection. Les mesures effectuées avec les chambres d'ionisation ont permis d'évaluer la valeur du débit de kerma dans l'air dans le faisceau de photons de haute énergie: celle-ci couvre une gamme entre $80 \mathrm{mGy} / \mathrm{h}$ et $210 \mathrm{mGy} / \mathrm{h}$, ce qui est compatible avec les besoins dans ce domaine. Enfin, nous avons calculé à l'aide de simulations Monte-Carlo des coefficients de conversion du kerma dans l'air vers les équivalents de dose pour des énergies de photons discrètes de $10 \mathrm{keV} \grave{a}$ 22,4 MeV dans des configurations géométriques spécifiques et pour la distribution spectrale de la fluence produite sur le LINAC du LNE-LNHB.

\section{Introduction}

Radiation protection of workers susceptible to be exposed to ionizing radiation requires the use of dosimeters type tested and calibrated in radiation fields covering all the encountered situations at one's workplace. For photon radiation, the radiation qualities to be used for type tests and calibrations are described in the international standard series ISO 4037. Moreover, in nuclear industry, dosimeters must be tested in high energy photon fields (mean energy of spectrum of 6 to $7 \mathrm{MeV}$ ).

A LNE-LNHB project was launched in order to design, construct and characterize a high energy photon field in order to meet the dosimeters manufacturers and users needs (Project Review 2014).

The international standard ISO 4037-1 [1] presents the production modes and the technical characteristics of radiation fields that are necessary for the characterization of these dosimeters for high-energy photons. There are few facilities providing high-energy photon fields for radiation protection standards and calibration purposes. The current work presents a new practical solution of setting such fields using a conventional radiotherapy linear accelerator (LINAC).

\section{State of the art}

In nuclear power plants and near the large accelerators, the workers might be exposed to high-energy photons ( $>2 \mathrm{MeV}$ ). In case of nuclear reactors, high-energy gamma fields are produced by the activation of oxygen in the primary circuit fluids (i.e. water in France, carbon dioxide in Great Britain). By an (n,p) reaction on ${ }^{16} \mathrm{O}$, fast neutrons produce ${ }^{16} \mathrm{~N}$, then its decay gives high energy photons, with an energy of 6.13 MeV (ISO 4037-1) [1].

Today, only the German (Calibration and Measurement Capabilities 2013) [2] and the Russian (Calibration and Measurement Capabilities 2014) [3] National Metrological Institutes dispose of photonic high energy beams for the characterization of dosimeters. The PTB beams are produced by the activation of Fluor and/or Carbon targets by a proton beam, the VNIIM beams are produced by a LINAC (maximum energy $10 \mathrm{MeV}$ ) and a betatron (maximum energy $50 \mathrm{MeV}$ ).

Radiation fields for radiation protection have to be characterized in terms of fluence and air kerma to derive the dose equivalents. Characterization in terms of air kerma using primary ionization chambers has already been performed at LNE-LNHB for photon beams used for radiation protection and radiotherapy $\left({ }^{137} \mathrm{Cs}\right.$ and ${ }^{60} \mathrm{Co}$ energies). Thus 6 primary cavity ionization chambers have been designed and built in 2008 at the LNE-LNHB [4]. The same design is used for this study. 
For the characterization in terms of dose equivalents of the radiation fields, the determination of conversion coefficients (from air kerma to dose equivalents) is needed. The average conversion coefficients are obtained through convolution of mono energetic conversion coefficients (CC) with the fluence spectra at the measurement point. The mono energetic CC's are available up to $10 \mathrm{MeV}$ in ICRU report 57 [5].

In this work, a new high-energy photon reference facility for radiation protection is dscribed, and a series of Monte Carlo calculations of the CC are presented to extend the range of available CC up to $22.4 \mathrm{MeV}$.

\section{High energy photon standard for radiation protection}

Our objective is to obtain a radiation field with a narrow distribution of fluence in terms of energy, of an equivalent energy of $6-7 \mathrm{MeV}$, homogenous in terms of dose equivalent and/or air kerma over a $30 \mathrm{~cm} \times 30 \mathrm{~cm}^{2}$ surface, centered at the point of measurement, and with dose equivalent rates compatible with radiation protection purposes.

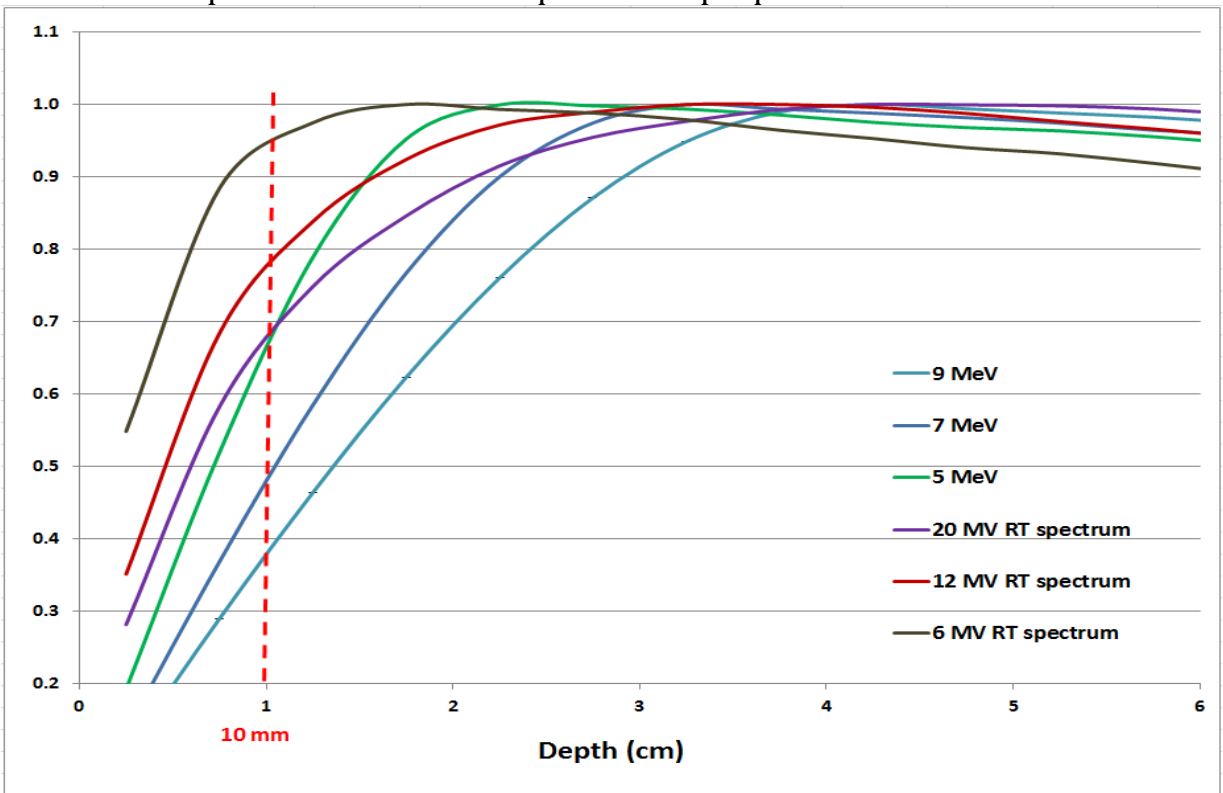

Figure 1. Depth dose normalized curves in a 'slab' phantom for mono energetic beams of 5, 6, 7, 8 and 9 $\mathrm{MeV}$ and radiotherapy spectra of 6,12 and $20 \mathrm{MV}$

As a first stage of our work, a series of normalized percentage depth dose curves for mono energetic beams of high-energy photons were calculated using MCNP5 code.

In these simulations, a large source (larger than $30 \mathrm{~cm} \times 30 \mathrm{~cm}$ ) emits a parallel and homogenous photon beam directed towards the entry facet of a 'slab' phantom of $30 \mathrm{~cm} \times 30 \mathrm{~cm} \times$ $15 \mathrm{~cm}$ made of tissue equivalent material (as defined by the ICRU [6]. The mono energetic photon beams are of 5,7 and $9 \mathrm{MeV}$, the same calculation were made with the three radiotherapy spectra of 6,12 and $20 \mathrm{MV}$ previously calculated in air, at the entry of a cubic, $30 \mathrm{~cm} \times 30 \mathrm{~cm} \times$ $30 \mathrm{~cm}$ water phantom [7]. As it can be seen in figure 1, the percentage depth dose normalized curves obtained with these three radiotherapy spectra are not superposed with those obtained with the mono energetic photon beams. This means that the radiotherapy spectra are unable to reproduce the behavior of a mono energetic high-energy photon beam. Nevertheless, the curve of the $20 \mathrm{MV}$ radiotherapy spectrum intercepts the $10 \mathrm{~mm}$ depth vertical line in the same region 
that the curve of the $5 \mathrm{MeV}$ beam. This clearly indicates that for a mean energy of about $6 \mathrm{MeV}$, the new high-energy photon beam for radiation protection could be obtained from a LINAC radiotherapy beam of about $20 \mathrm{MV}$, taking care of a consequent reduction of low photon energies by the use of a specifically designed target.

Therefore, a beam of high-energy photons can be obtained by the slowdown of an electron beam, on a metal target of high atomic number (needed in order to favor energy loss by bremsstrahlung). In this work, we use high-energy electrons (18 MeV) supplied by the medical linear accelerator Delphes of LNE-LNHB in order to obtain high-energy photons. In order to "harden" the spectrum of photons (i.e. to reduce the proportion of low-energy photons), the high atomic number material of the target is supplemented by a material of low atomic number.

Interaction of an $18-\mathrm{MeV}$ electron beam with several combinations of high-Z materials (tungsten, lead, gold, copper) and low-Z materials (graphite, beryllium) with various thicknesses were studied. A thorough analysis of the obtained simulated results showed that the best hardening of the spectrum and the best air kerma rate reduction was obtained with a layer of tungsten thick of about $1.1 \mathrm{~cm}$, followed by a layer of graphite of about $7.8 \mathrm{~cm}$ thick. However, for practical reasons (related to the cost and to the weight of the material), copper has been used as material for our target, still allowing good performance compared to tungsten. Prior to the design of a proper shape of the conversion target, we have conducted preliminary experiments on several prototype $\mathrm{Cu}-\mathrm{C}$ conversion targets (a $14 \mathrm{~mm} \mathrm{Cu}$ target, a $28 \mathrm{~mm} \mathrm{Cu}$ target; a mixed $28 \mathrm{~mm} \mathrm{Cu}$ and $64 \mathrm{~mm}$ graphite conversion target). It ended that by simulating the interaction between an electron beam of $18 \mathrm{MeV}$ with a copper-graphite conversion target $(3.6 \mathrm{~cm}$ of copper and $15.7 \mathrm{~cm}$ of graphite), a spectrum of average energy weighted by fluence of $5.79 \mathrm{MeV}$ was obtained. In this configuration, the electrons beam incident on the conversion target is of $7.5 \mathrm{~cm}$ $\times 7.5 \mathrm{~cm}$. The geometric shape of the target should be adjusted in order to obtain a uniform beam on a surface of $30 \mathrm{~cm} \times 30 \mathrm{~cm}$ at a distance of $1 \mathrm{~m}$ from the entry point to the target. The resulting simulated profiles lead to a particular shape of the $\mathrm{Cu}-\mathrm{C}$ target. In order to obtain a homogeneous ambient dose equivalent distribution $( \pm 2 \%)$ on an area of $30 \times 30 \mathrm{~cm}^{2}$, the target is thicker in its central part than at its edges. This is true for both materials constituting the target, and the radial symmetry of the system directed us to superpose conical structures. Several successively adjusted models were simulated in order to set the final design of the target shown in Figure 2.

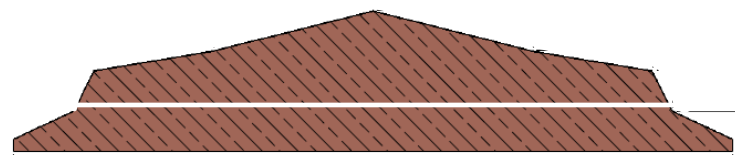

Copper target

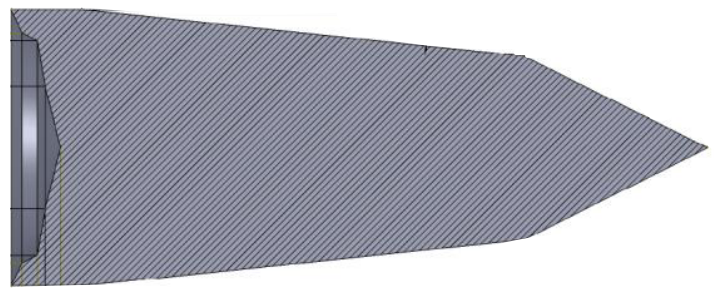

Graphite filter

Figure 2. Final design of the conversion target

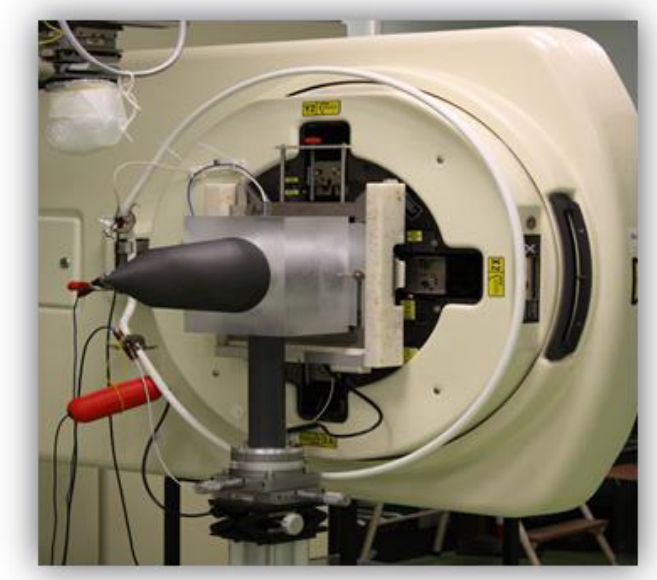


The average energy weighted by fluence $\overline{E_{\Psi}}$ of the spectrum obtained by simulation with the final design of the target is of $6.17 \mathrm{MeV}$. The average energy weighted by energy fluence of this spectrum is equal to $9.02 \mathrm{MeV}$. The two average energies are given by the formulae:

$$
\overline{E_{\Phi}}=\frac{\int E \times \frac{d \Phi}{d E} d E}{\int \frac{d \Phi}{d E} d E}
$$$$
\overline{E_{\Psi}}=\frac{\int E \times E \times \frac{d \Phi}{d E} d E}{\int E \times \frac{d \Phi}{d E} d E}
$$

With this target, the distribution of air kerma is relatively uniform $( \pm 2 \%$ compared to the mean value) along the horizontal and the vertical axis in the range of $-15 \mathrm{~cm}$ to $15 \mathrm{~cm}$. The radiation protection spectrum in air is presented in the Figure 3 here below (the contribution of low energies yields to $\sim 2 \%$ of the total air kerma).

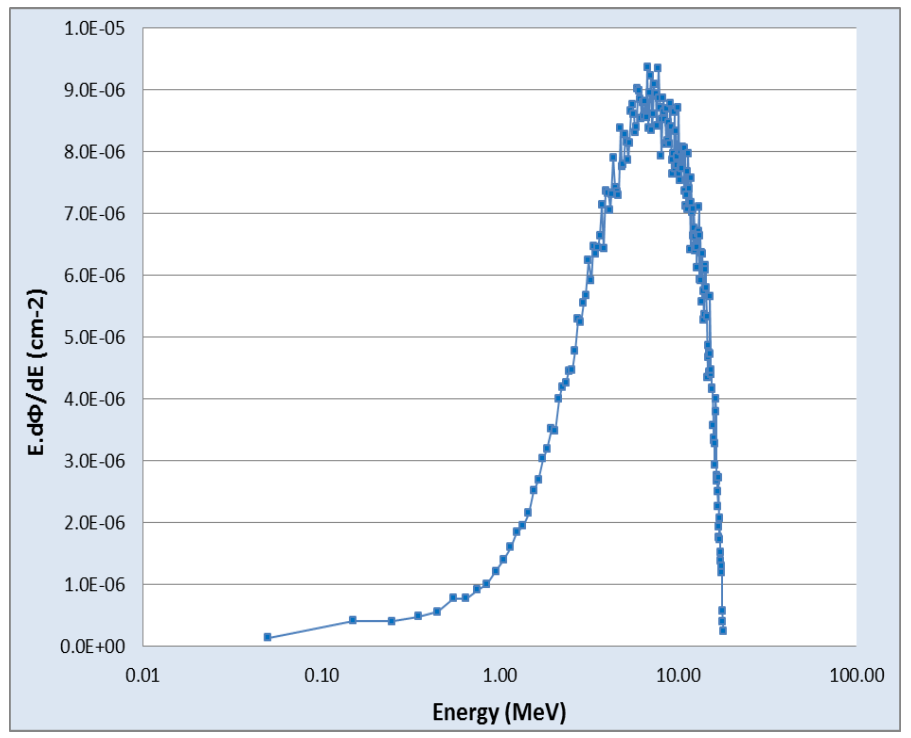

Figure 3. High-energy photon radiation protection spectrum

As an example the horizontal profile calculated over $+/-15 \mathrm{~cm}$ at a distance of $1 \mathrm{~m}$ from the target's entry facet, is shown in figure 4 . The maximum difference in respect to the average value of the air kerma is of about 3\%. The air kerma presents a similar distribution along the vertical axis over the same range. The homogeneity of the simulated beam is therefore sufficient on a $30 \mathrm{~cm} \times 30 \mathrm{~cm}^{2}$ surface at the measurement distance.

\section{Primary standard for the high energy photon beam for radiation protection}

The LNE-LNHB has designed and built in 2008 a series of six primary cavity ionization chambers adapted to common radiation protection and radiotherapy beams $\left({ }^{60} \mathrm{Co},{ }^{137} \mathrm{Cs}\right)$. These chambers have been used for the establishment of French primary standards in these beams in terms of air kerma. A primary dosimeter for the high-energy photon beam for radiation protec- 
tion has been built using the same design [8] as one of the existing primary spherical ionizing chambers (Figure 5). Its external wall and internal electrode are made of graphite, the charge collection volume of this new chamber has been determined in the laboratory. The average absorbed dose in the cavity of an air-filled chamber is given by the following expression.

$$
\bar{D}_{\text {air }}=\frac{1}{\rho_{\text {air }} V} \frac{Q}{e} W
$$

where $Q$ is the electrical charge created in the cavity by the ionization of the gas by the radiation, $e$ is the elementary charge, $\rho_{\text {air }}$ is the density of air, $V$ is the cavity's charge collection volume, and $W$ is the average energy needed for the creation of an ion pair in the gas (in our case, the gas is the air, identical to the ambient air, as the chamber has a hole allowing for the circulation of the air in and out of the chamber, thus called "open geometry" chamber).

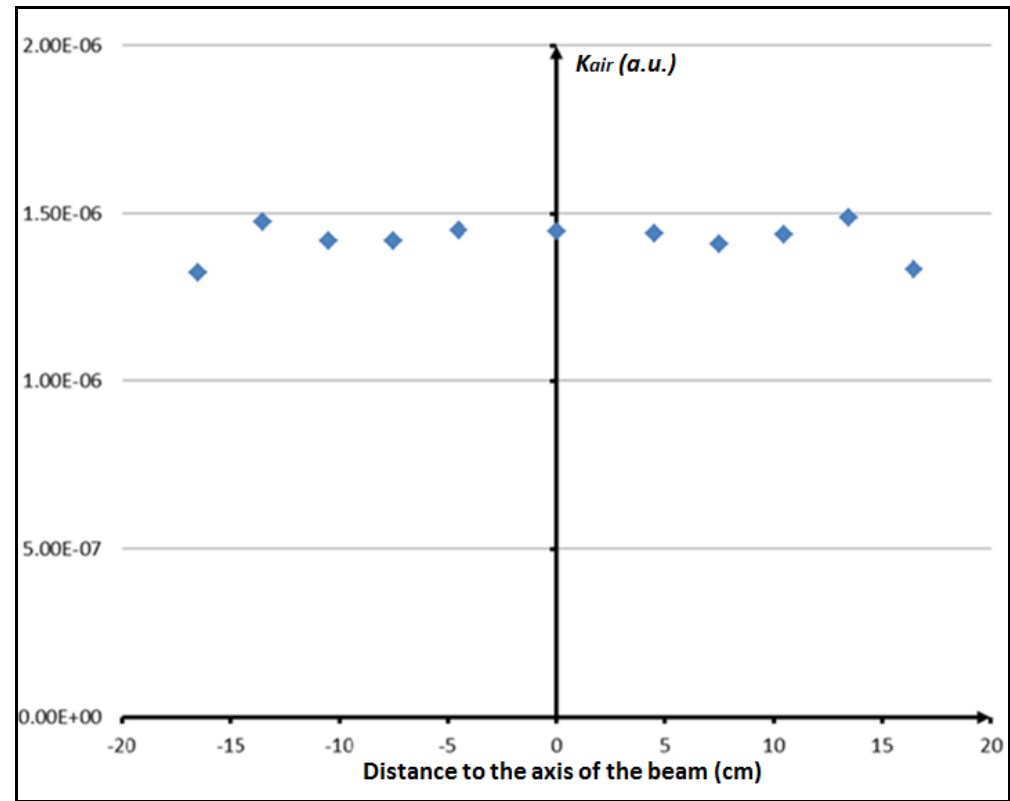

Figure 4. Horizontal profile of the beam in terms of air kerma at $1 \mathrm{~m}$ from the entry facet of the target
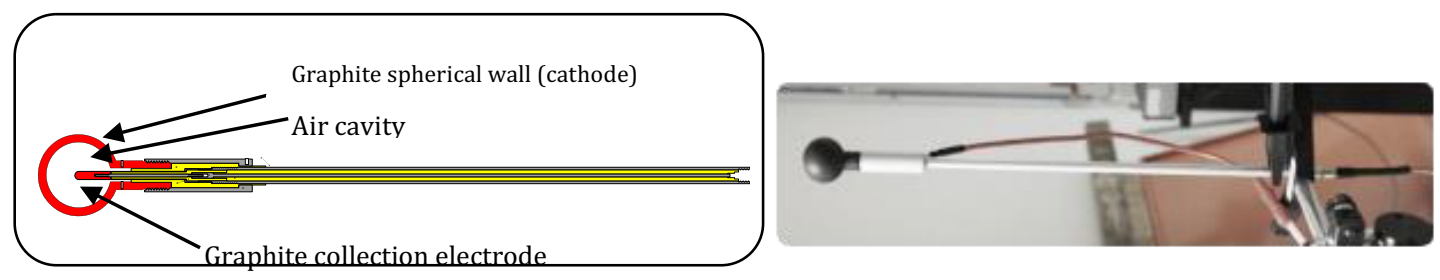

Figure 5. Primary ionization chamber

The functioning of the ionization chamber has been tested by electrical characterization measurements in a reference isotopic beam $\left({ }^{60} \mathrm{Co}\right)$. Recombination and polarity correction factors for this chamber are close to unity (1.0016 and, respectively, 1.0006), thus proving a good electrical performance of the chamber.

The characterization of the ionization chamber has been continued in the LINAC beam. The optimal polarization voltage has been measured; its value is of +850 volts. The stability of the signal over time has been tested; it is better than $0.13 \%$ and does not have systematic drift. The 
graphite wall of the chamber is thick enough $(3 \mathrm{~mm})$ to ensure electron equilibrium in a ${ }^{60} \mathrm{Co}$ beam, but not in the case of a energy LINAC beam. This problem is resolved by using a thick graphite electron equilibrium cap $(27 \mathrm{~mm})$. All subsequent reference measurements have been realized with this cap.

A first evaluation of the air kerma rate in the LINAC beam has been performed with this reference ionization chamber. Measurements of ionization currents have been normalized to the indications of the monitor ionization chamber, expressed in terms of Monitor Units (MU). The air kerma rate is then measured in grays per MU. It is expressed by the following.

$$
\left.\dot{K}_{\text {air } / U M}=Q_{\text {ref } / M U}^{*} \cdot \frac{1}{\rho_{\text {air }} V} \cdot \frac{W}{e} \cdot S_{\text {graphite, air }} \cdot \mu_{e n} / \rho\right)_{\text {air, graphite }} \cdot \frac{1}{A_{\text {graphite }}} \cdot \frac{1}{1-\bar{g}}
$$

where:

$M U$ is the charge corrected by temperature, pressure and humidity of the LINAC monitor ionizing chamber,

the " $/ M U$ " index in a quantity indicates that the quantity is divided by the $M U$ charge,

$Q^{*}$ ref is the charge $Q_{\text {ref }}$ measured by the reference chamber, corrected of the leakage current, of climate conditions (temperature, pressure, humidity), electrical factors (recombination, polarity) and of the non-punctual chamber (diffusion in the chamber's stem, and radial and axial anisotropy of the beam),

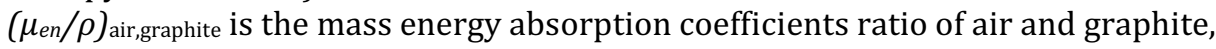

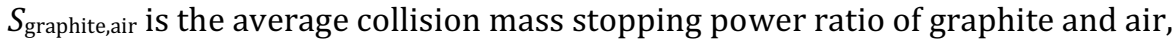
$A_{\text {graphite }}$ is the correction factor due to the graphite wall (attenuation and diffusion of photons), $\overline{\mathrm{g}}$ is the fraction of energy going into bremsstrahlung.

The values of the air kerma rate and the associated uncertainty and of intermediate terms are presented in Table 1.

Table 1. Determination of the reference air kerma rate

\begin{tabular}{|c|c|c|}
\hline Quantities & Values & Uncertainty $(\mathrm{k}=1, \%)$ \\
\hline$Q_{\text {réf/MU }}^{*}(\mathrm{C} / \mathrm{MU})$ & $1.101510^{-1}$ & 0.40 \\
\hline$A_{\text {graphite }}$ & $9.48510^{-1}$ & 0.21 \\
\hline Volume $\left(\mathrm{m}^{3}\right)$ & $4.140510^{-6}$ & 0.037 \\
\hline $\boldsymbol{\rho}_{\text {air }}\left(\mathrm{kg} / \mathrm{m}^{3}\right)\left(\right.$ dry air, $\left.20^{\circ} \mathrm{C}, 1013,25 \mathrm{hPa}\right)$ & 1.2047 & 0.001 \\
\hline W/e $S_{\text {graphite,air }}(\mathrm{J} / \mathrm{C}$ ) & 32.18 & 0.93 \\
\hline$\left(\mu_{e n} / \rho\right)_{\text {air,graphite }}$ & 1.038 & 1.5 \\
\hline $1 /(1-\bar{g})$ & 1.024 & 1.4 \\
\hline$\dot{K}_{\text {air }}(\mathrm{Gy} / \mathrm{h})$ & $7.9610^{5}$ & 2.3 \\
\hline
\end{tabular}

Detailed correction factors (other than climate factors) to be applied to $Q_{\text {ref }}$ and their associated uncertainties are presented in Table 2.

The air kerma rate, expressed in grays per unit time was estimated using the average quantity of charge measured by the monitor per minute $\left(\sim 4.32 \times 10^{-9} \mathrm{MU} / \mathrm{min}\right)$. The air kerma rate is $\sim 200 \mathrm{mGy} / \mathrm{h}$ at $1.45 \mathrm{~m}$ from the virtual point source. The results are resumed in the Table 3 . 
Table 2. Correction factors applied to the measured charge, corrected of climate conditions, and associated uncertainties.

\begin{tabular}{|c|c|c|}
\hline Factors & Values & Uncertainty $(\mathrm{k}=1, \%)$ \\
\hline Polarity, $k_{\text {pol }}$ & 1.0006 & 0.051 \\
\hline Recombination, $k_{r e c}$ & 1.0016 & 0.097 \\
\hline Stem, $k_{s t}$ & 0.9997 & 0.32 \\
\hline Radial anisotropy, $k_{r n}$ & 1.0000 & 0.14 \\
\hline Axial anisotropy, $k_{a n}$ & 1.0000 & 0.025 \\
\hline
\end{tabular}

Table 3. Estimation of the measured air kerma rate per time unit.

\begin{tabular}{|c|c|c|}
\hline Measurement distance & Current I (A) & $\dot{K}_{\text {air }}(\mathrm{Gy} / \mathrm{h})$ \\
\hline $1.45 \mathrm{~m}$ (reference) & $-7.92510^{-12}$ & $2,064(46) 10^{-1}$ \\
\hline $3.45 \mathrm{~m}$ & $-1.39810^{-12}$ & $3,641(82) 10^{-2}$ \\
\hline
\end{tabular}

The reference values of the air kerma rate in this beam and the conversion coefficients (section 6) allow calculating radiation protection operational quantities.

\section{Realization and calibration of a transfer dosimeter for the high energy photon beam for radiation protection}

An ionization chamber, identical to the primary ionization chamber described above, has been built. The current measurements for the calibration of this chamber have been performed in the same conditions as those described in the previous chapter, using an electron equilibrium cap (27 mm thickness). The characteristics of the chamber in terms of recombination, polarity and leakage currents were studied giving the same results as those of the chamber used for the primary measurements.

This chamber has been calibrated in the ${ }^{60} \mathrm{Co}$ beam of the LNE-LNHB (Figure 6), using an ionometric chain (electrometer, cables, etc.). The calibration coefficient, $N_{\text {Kair,60Co, }}$ is $7.66 \times 10$ Gy/C, with an uncertainty of $0.64 \%(k=2)$ (LNHB Calibration Certificate No. 103141, 2014). The measurements performed in the LINAC beam resulted in the following calibration coefficient: $N_{\text {Kair,LINAC }}=6.92 \times 10^{6} \mathrm{~Gy} / \mathrm{C}$, with an uncertainty of $4.5 \%(k=2)$ (LNHB Calibration Certificate No. 103142, 2014).

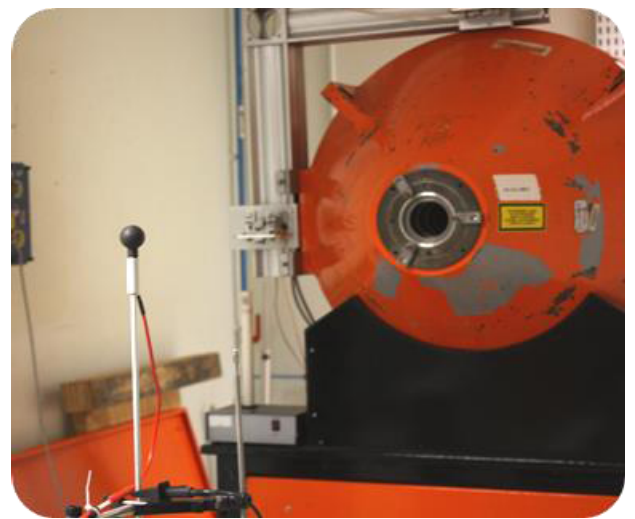

Figure 6. Ionization chamber in the ${ }^{60} \mathrm{Co}$ beam of LNE-LNHB 


\section{Calculations of conversion coefficients}

Conversion coefficients (CC) relate physical quantities and operational quantities. Physical quantities for dosimetry of ionizing radiation are the fluence $(\Phi)$, the kerma $(K)$ and the absorbed dose $(D)$. Dose equivalents (ambient $H^{*}(10)$ or personal $H_{p}(10)$ ) are the operational quantities used for strongly penetrating radiation $[9,10]$. Conversion coefficients $\left(k_{\Phi}\right)$ and $\left(h_{k}\right)$ allow obtaining air kerma from fluence and dose equivalent from air kerma, respectively.

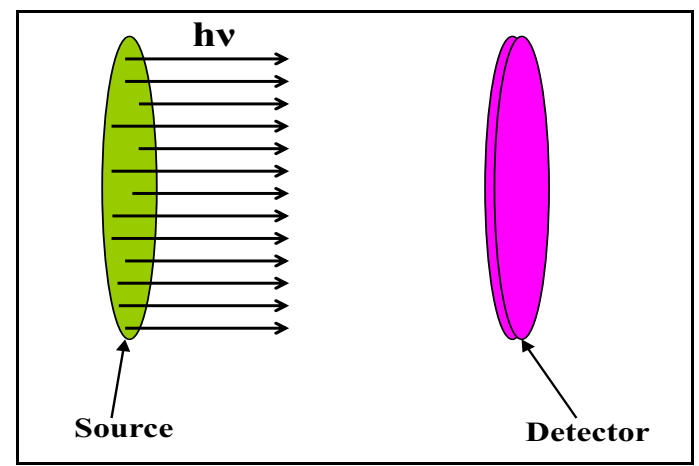

Figure 7. Geometry used for the calculation of $k_{\phi}$

$$
k_{\Phi}=\frac{K_{a i r}}{\Phi}\left(\mathrm{pGy} \cdot \mathrm{cm}^{2}\right) \quad \text { (5) } \quad h_{k}=\frac{H / \Phi}{K_{a i r} / \Phi}(\mathrm{Sv} / \mathrm{Gy})
$$

The values of the mono energetic CC are given in ICRU 57 report (ICRU no. 57 1998) up to $10 \mathrm{MeV}$ for photons. For the purpose of the present work values up to $18 \mathrm{MeV}$ are needed, so we calculated them and made a comparison of our calculations with the values of ICRU 57. The conversion coefficient $k_{\Phi}$ is evaluated in a simplified geometry (Figure 7). The source is homogenously distributed over a thin disc of $15 \mathrm{~cm}$ radius. The detector is a disc of dry air (composition defined by ICRU) of $15 \mathrm{~cm}$ radius and a thickness of $0.05 \mathrm{~cm}$ (Figure 7). The source and the detector are in vacuum.

The conversion coefficients for ambient dose equivalent $h_{k}^{*}(10)$ are evaluated in a geometry using the phantom, currently named "ICRU sphere", defined in ICRU Report 39 (ICRU no. 39 1985). This phantom is a sphere of $15 \mathrm{~cm}$ radius made of 4-element tissue equivalent material, having a density of $1 \mathrm{~g} / \mathrm{cm}^{3}$ (ICRU no. 47 1992) (Figure 8). The conversion coefficients for personal dose equivalent $h_{k, p}(10)$ are evaluated in a geometry using the phantom, currently named "ICRU slab phantom". This phantom has been defined by ICRU: it is a parallelepiped slab of 30 $\mathrm{cm} \times 30 \mathrm{~cm} \times 15 \mathrm{~cm}$, in the same 4-element tissue equivalent material (ICRU no. 47 1992) (Figure 9). 


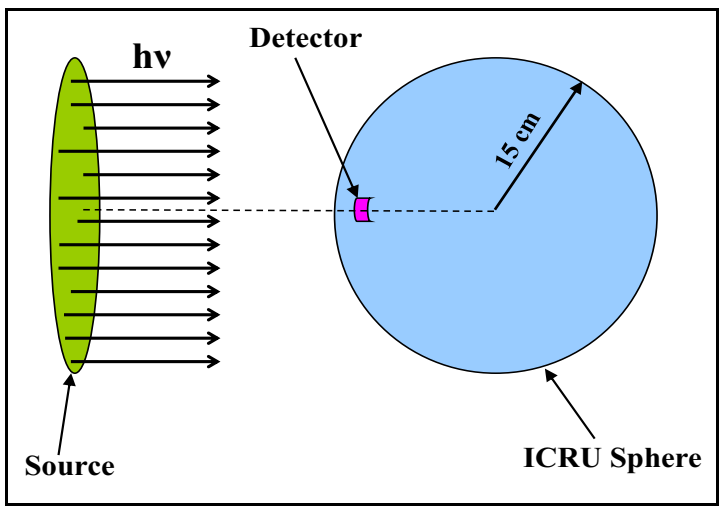

Figure 8. Geometry used for the calculation of $h^{*}{ }_{\Phi}(10)$ and $h^{*}{ }_{\mathrm{k}}(10)$

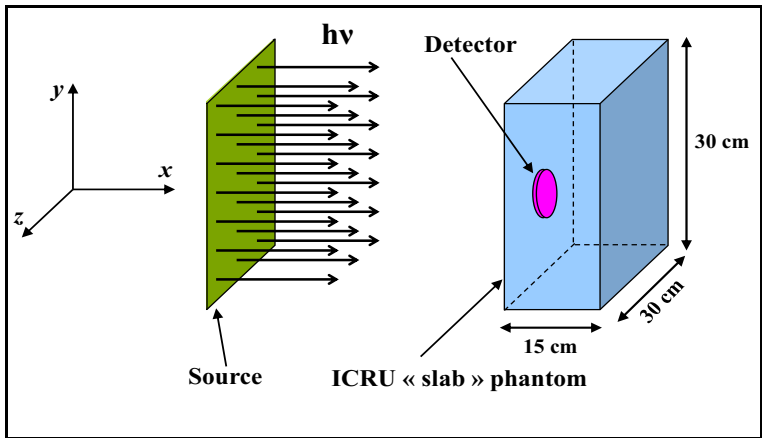

Figure 9. Geometry used for the calculation of $h_{\Phi, \mathrm{p}}(10)$ and $h_{\mathrm{k}, \mathrm{p}}(10)$

The dose equivalent is related to the absorbed dose by a simple formula: $H=Q \cdot D$, where $Q$ is the average quality factor. For photons, this average quality factor equals to 1 [11]. Therefore, the absorbed dose to tissue, expressed in Gy, is numerically equal to the dose equivalent, expressed in Sv.

The numerical Monte Carlo simulations have been performed with the MCNP5 (X-team 5, MCNP 2003) [12] and PENELOPE 2008 [13] codes. The geometries described above are simulated with both codes, and the number of particles followed is chosen in order to achieve a sufficiently low uncertainty. The MCNP5 code uses the following cross-section libraries: MCPLIB0 4 for photons, and EL03 for electrons (LLNL EPDL 1997) [14]. Photoelectric cross-sections used by the PENELOPE 2008 code are those of the EPDL 97 library (LLNL EPDL 1997).

Incident photon energy for the evaluation of mono energetic conversion coefficients ranges from $10 \mathrm{keV}$ to $22 \mathrm{MeV}$. This energy range is significantly larger (low and high energy) than the energy range used in the ICRU 57 Report (10 keV - $10 \mathrm{MeV}$ ) (ICRU no. 57 1998). MCNP5 and PENELOPE 2008 codes use more recent cross-sections libraries than those that have been used in order to obtain the conversion coefficients given in ICRU 57 Report. Moreover, all the results presented in ICRU 57 Report have been calculated in a "kerma approximation", i.e. considering that the secondary electrons created by photons deposit their energy locally. For high-energy photons, in an energy range where electronic equilibrium is fulfilled at $10 \mathrm{~mm}$ depth, we have: $K_{T} \approx D_{T}$ ( $K_{T}$ is the kerma in tissue and $D_{T}$ is the absorbed dose in tissue). Therefore, numerically, $H^{*}(10) \approx K_{T}$ and $H_{p}(10) \approx K_{T}$. In an energy range where electronic equilibrium is not yet established, we have: $D_{T}<K_{T}$. Therefore, numerically, $H^{*}(10)<K_{T}$ and $H_{p}(10)<K_{T}$.

Electronic equilibrium is reached at a depth greater than the practical range of the electrons. In our calculations, the "detector" is situated at a depth of $10 \mathrm{~mm}$, inside the phantom in tissue equivalent material. After the evaluation of the range of electrons in the tissue equivalent 
material by Monte Carlo simulations in MCNP5, we have concluded that for this depth, the electronic equilibrium is not ensured for energy higher than $2 \mathrm{MeV}$. This point has been already underlined for $H_{p}(3)$ quantity for photon energies higher than $1 \mathrm{MeV}$ [15]. Thus, for incident photon energy above $2 \mathrm{MeV}$, the "kerma approximation" and the absorbed dose calculations are significantly different. By carefully choosing the cut-off energies for electrons and positrons in PENELOPE 2008 (50 keV) and evaluating the appropriate tallies in MCNP5 (i.e. tally F6 for air kerma calculations and tally *F8 for absorbed dose calculations), we have calculated the mono energetic conversion coefficients (from fluence or from air kerma to dose equivalent) in "kerma approximation", and also in terms of the absorbed dose, $D_{T}$.

\section{Results and Discussions}

In the great majority of cases, a good agreement was obtained between MCNP5 and PENELOPE 2008: the difference between values obtained by the two codes is generally smaller than $0.5 \%$. In Tables 4 , and 5 the calculated values of several conversion coefficients, in "kerma approximation" and in terms of absorbed dose are presented for mono energetic photons. The values of the coefficients presented in these three tables are mean values of coefficients calculated by MCNP5 and by PENELOPE 2008 calculation.

The conversion coefficients have been compared to the data from the ICRU 57 Report (ICRU no. 57 1998) for photon energy up to $10 \mathrm{MeV}$. In the range $10 \mathrm{keV}-2 \mathrm{MeV}$, we have found a good agreement between the coefficients calculated in "kerma approximation" and in absorbed dose, with those presented in the ICRU 57 Report. According to Table 6 for the $h_{k}^{*}(10)$ coefficients, for the energies equal to or greater than $3 \mathrm{MeV}$, only the coefficients obtained in "kerma approximation" are close to the values reported in ICRU 57 (Table A.21., pp 179).

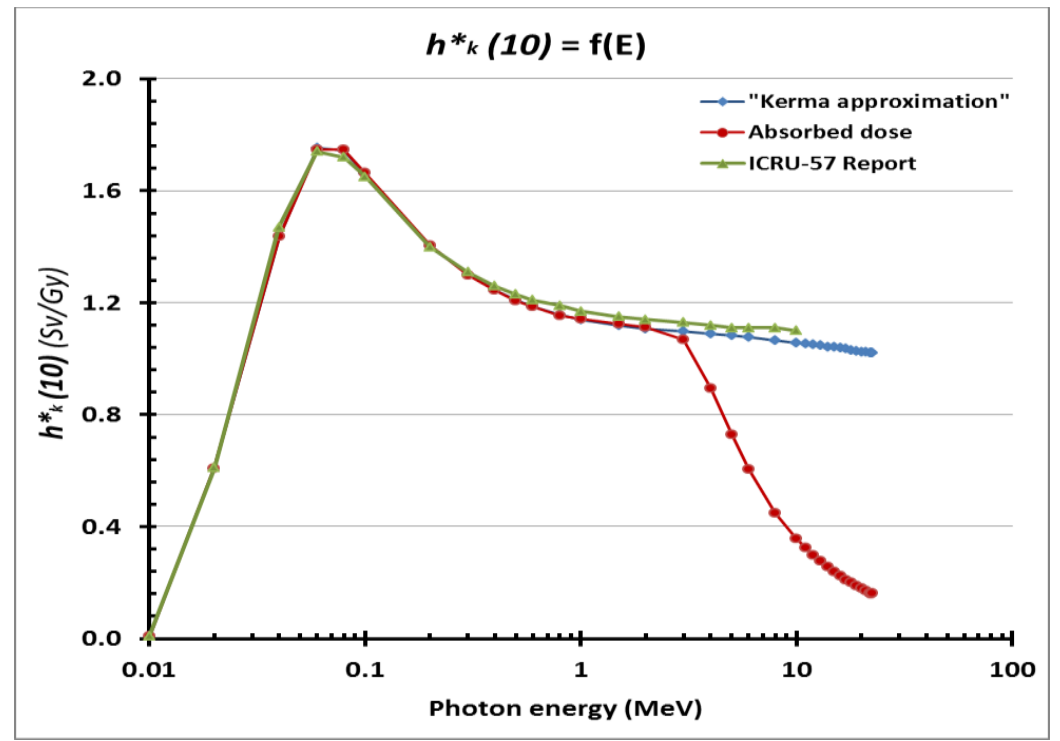

Figure 10. $h^{*}{ }_{\mathrm{k}}(10)$ values as function of energy (in "kerma approximation", in absorbed dose calculations and according to the ICRU-57 Report)

In the range $3 \mathrm{MeV}-22.4 \mathrm{MeV}$, the difference between the conversion coefficients $h^{*} \mathrm{k}(10)$ obtained in "kerma approximation" and in absorbed dose calculations increases sharply with the energy. This is explained by the fact that for the high energies of photons the build-up dis- 
tances of secondary electrons is considerably higher than $10 \mathrm{~mm}$. The curves in Figure 10 show these differences for the $h^{*}{ }_{k}(10)$ coefficients.

Table 4. Conversion coefficients $h_{\mathrm{k}}^{*}$ obtained in absorbed dose calculations, average value of MCNP5 and PENELOPE 2008 calculations

\begin{tabular}{|c|c|c|c|c|}
\hline $\begin{array}{l}\text { Photon en- } \\
\text { ergy (MeV) }\end{array}$ & $\begin{array}{l}\text { Mean } h^{*} \phi(10) \text { coef- } \\
\text { ficients }\left(\mathrm{pSv} \cdot \mathrm{cm}^{2}\right)\end{array}$ & $\begin{array}{l}\text { Mean } h^{*}{ }_{k}(10) \text { coeffi- } \\
\text { cients (Sv/Gy) }\end{array}$ & $\begin{array}{l}\text { Mean } h_{\phi . p}(10) \text { coef- } \\
\text { ficients }\left(\mathrm{pSv} \cdot \mathrm{cm}^{2}\right)\end{array}$ & $\begin{array}{l}\text { Mean } h_{k . p}(10) \text { coeffi- } \\
\text { cients (Sv/Gy) }\end{array}$ \\
\hline 0.01 & 0.064 & 0.008 & 0.064 & 0.008 \\
\hline 0.02 & 1.049 & 0.607 & 1.055 & 0.611 \\
\hline 0.04 & 0.631 & 1.437 & 0.660 & 1.504 \\
\hline 0.06 & 0.512 & 1.749 & 0.557 & 1.901 \\
\hline 0.08 & 0.539 & 1.747 & 0.588 & 1.906 \\
\hline 0.1 & 0.620 & 1.663 & 0.676 & 1.814 \\
\hline 0.2 & 1.204 & 1.404 & 1.281 & 1.495 \\
\hline 0.3 & 1.796 & 1.300 & 1.895 & 1.371 \\
\hline 0.4 & 2.360 & 1.246 & 2.470 & 1.304 \\
\hline 0.5 & 2.874 & 1.206 & 3.000 & 1.259 \\
\hline 0.6 & 3.378 & 1.186 & 3.491 & 1.226 \\
\hline 0.8 & 4.282 & 1.154 & 4.408 & 1.188 \\
\hline 1 & 5.126 & 1.142 & 5.249 & 1.169 \\
\hline 1.5 & 6.922 & 1.125 & 7.041 & 1.144 \\
\hline 2 & 8.418 & 1.113 & 8.541 & 1.129 \\
\hline 3 & 10.647 & 1.068 & 10.784 & 1.082 \\
\hline 4 & 10.851 & 0.894 & 10.970 & 0.904 \\
\hline 5 & 10.320 & 0.728 & 10.469 & 0.739 \\
\hline 6 & 9.773 & 0.604 & 9.925 & 0.613 \\
\hline 8 & 9.051 & 0.450 & 9.175 & 0.456 \\
\hline 10 & 8.646 & 0.358 & 8.788 & 0.364 \\
\hline 11 & 8.518 & 0.326 & 8.634 & 0.330 \\
\hline 12 & 8.429 & 0.299 & 8.529 & 0.303 \\
\hline 13 & 8.384 & 0.277 & 8.441 & 0.279 \\
\hline 14 & 8.284 & 0.256 & 8.423 & 0.261 \\
\hline 15 & 8.223 & 0.239 & 8.334 & 0.242 \\
\hline 16 & 8.171 & 0.223 & 8.336 & 0.228 \\
\hline 17 & 8.145 & 0.210 & 8.283 & 0.214 \\
\hline 18 & 8.206 & 0.201 & 8.270 & 0.202 \\
\hline 19 & 8.154 & 0.189 & 8.278 & 0.192 \\
\hline 20 & 8.134 & 0.179 & 8.214 & 0.181 \\
\hline 21 & 8.118 & 0.171 & 8.256 & 0.174 \\
\hline 22 & 8.151 & 0.164 & 8.244 & 0.165 \\
\hline
\end{tabular}


Table 5. Conversion coefficients $h^{*}{ }_{k}$ obtained in "kerma approximation" calculations, average value of MCNP5 and PENELOPE 2008 calculations.

\begin{tabular}{|c|c|c|c|c|}
\hline $\begin{array}{l}\text { Photon ener- } \\
\text { gy (MeV) }\end{array}$ & $\begin{array}{l}\text { Mean } h^{*} \phi(10) \text { coeffi- } \\
\text { cients }\left(\mathrm{pSv} \cdot \mathrm{cm}^{2}\right)\end{array}$ & $\begin{array}{c}\text { Mean } h^{*}{ }_{k}(10) \text { coeffi- } \\
\text { cients (Sv/Gy) }\end{array}$ & $\begin{array}{l}\text { Mean } h_{\phi . p}(10) \text { coef- } \\
\text { ficients }\left(\mathrm{pSv} \cdot \mathrm{cm}^{2}\right)\end{array}$ & $\begin{array}{c}\text { Mean } h_{k . p}(10) \text { coeffi- } \\
\text { cients }(\mathrm{Sv} / \mathrm{Gy})\end{array}$ \\
\hline 0.01 & 0.064 & 0.008 & 0.064 & 0.008 \\
\hline 0.02 & 1.051 & 0.608 & 1.054 & 0.610 \\
\hline 0.04 & 0.630 & 1.437 & 0.658 & 1.501 \\
\hline 0.06 & 0.514 & 1.753 & 0.556 & 1.897 \\
\hline 0.08 & 0.539 & 1.745 & 0.589 & 1.908 \\
\hline 0.1 & 0.620 & 1.663 & 0.675 & 1.812 \\
\hline 0.2 & 1.201 & 1.402 & 1.281 & 1.494 \\
\hline 0.3 & 1.797 & 1.300 & 1.892 & 1.369 \\
\hline 0.4 & 2.358 & 1.245 & 2.464 & 1.301 \\
\hline 0.5 & 2.886 & 1.211 & 2.996 & 1.257 \\
\hline 0.6 & 3.384 & 1.188 & 3.495 & 1.227 \\
\hline 0.8 & 4.296 & 1.158 & 4.410 & 1.188 \\
\hline 1 & 5.114 & 1.139 & 5.234 & 1.166 \\
\hline 1.5 & 6.883 & 1.118 & 6.991 & 1.136 \\
\hline 2 & 8.381 & 1.108 & 8.483 & 1.122 \\
\hline 3 & 10.934 & 1.097 & 11.054 & 1.109 \\
\hline
\end{tabular}

Table 5 continue. Conversion coefficients $h^{*}{ }_{k}$ obtained in "kerma approximation" calculations, average value of MCNP5 and PENELOPE 2008 calculations.

\begin{tabular}{|c|c|c|c|c|}
\hline 4 & 13.219 & 1.089 & 13.304 & 1.096 \\
\hline 5 & 15.372 & 1.084 & 15.424 & 1.088 \\
\hline 6 & 17.410 & 1.076 & 17.484 & 1.080 \\
\hline 8 & 21.462 & 1.066 & 21.565 & 1.072 \\
\hline 10 & 25.468 & 1.056 & 25.556 & 1.059 \\
\hline 11 & 27.531 & 1.053 & 27.610 & 1.056 \\
\hline 12 & 29.569 & 1.050 & 29.629 & 1.052 \\
\hline 13 & 31.661 & 1.047 & 31.666 & 1.047 \\
\hline 14 & 33.705 & 1.043 & 33.743 & 1.044 \\
\hline 15 & 35.815 & 1.040 & 35.803 & 1.040 \\
\hline 16 & 37.976 & 1.039 & 37.910 & 1.037 \\
\hline 17 & 40.074 & 1.035 & 40.077 & 1.035 \\
\hline 18 & 42.097 & 1.029 & 42.259 & 1.033 \\
\hline 19 & 44.292 & 1.028 & 44.389 & 1.030 \\
\hline 20 & 46.447 & 1.025 & 46.616 & 1.029 \\
\hline 21 & 48.689 & 1.023 & 48.843 & 1.027 \\
\hline 22 & 50.844 & 1.021 & 51.098 & 1.026 \\
\hline
\end{tabular}

In Figure 10 a difference between the $h_{k}^{*}(10)$ coefficients calculated in "kerma approximation" and tabulated in the ICRU 57 Report (Table A.21., pp. 179) is visible for energies higher than $300 \mathrm{keV}$. These disparities arise from slightly different values of the $K_{\text {air }} / \Phi$ quantity (used to determine the value of the $h^{*}{ }_{k}(10)$ coefficients), as can be seen in table 7 .

The values of $k_{\phi}$ in Table A.1 have been obtained using input data from 1982, whilst the values of $k_{\Phi}$ in Table A.21 have been obtained using input data from 1995. The largest difference between these two sets is of $\sim 3.5 \%$. The largest difference between the values of the $h_{k}^{*}(10)$ coefficients presented in Table 6 is of $\sim 3,8 \%$. We therefore conclude that this difference may be explained by the difference between the two sets of air kerma..

A similar comparison of coefficients has been performed for another set of conversion coefficients: $h_{k, p}(10)$. In the same manner as for the $h_{k}^{*}(10)$ coefficients, in the range $10 \mathrm{keV}-2 \mathrm{MeV}$, 
we have found a good agreement between the coefficients calculated in "kerma approximation" and in absorbed dose, with those presented in the ICRU 57 Report. According to Table 8 presented here below for the $h_{k, p}(10)$ coefficients, for the energies equal to or greater than $3 \mathrm{MeV}$, only the coefficients obtained in "kerma approximation" are close to the values reported in ICRU 57 (Table A.24., pp 182).

As for the $h^{*}{ }_{k}(10)$ coefficients, in the range $3 \mathrm{MeV}-22.4 \mathrm{MeV}$, the difference between the conversion coefficients $h_{k, p}(10)$ obtained in "kerma approximation" and in absorbed dose calculations increases sharply with the energy due to the build-up depth of secondary electrons considerably higher than $10 \mathrm{~mm}$ above $3 \mathrm{MeV}$. The curves in Figure 5 show these differences for the $h_{k, p}(10)$ coefficients.

In Figure 11 a difference between the $h_{k, p}(10)$ coefficients calculated in "kerma approximation" and tabulated in the ICRU - 57 Report (Table A.24., pp. 182) is visible for energies higher than $2 \mathrm{MeV}$. As for the $h^{*}{ }_{k}(10)$ coefficients, it is explained by the difference between the two sets of air kerma values.

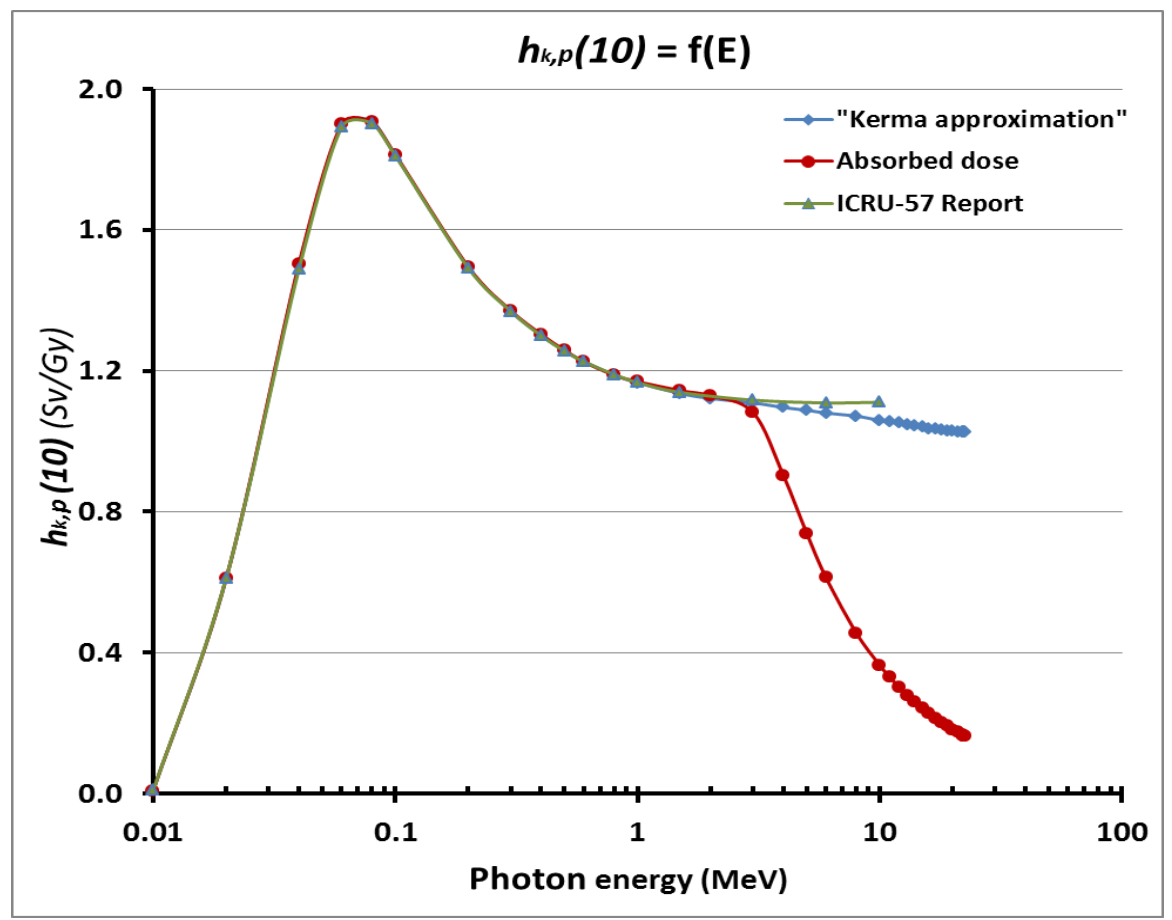

Figure 11. $h_{k, p}(10)$ values as function of energy (in "kerma approximation", in absorbed dose calculations and according to the ICRU-57 Report) 
Table 6. Air kerma - ambient dose equivalent conversion coefficients calculated in absorbed dose, in "kerma approximation" and in ICRU-57 Report

\begin{tabular}{|c|c|c|c|}
\hline $\begin{array}{c}\text { Photon energy } \\
(\mathrm{MeV})\end{array}$ & $\begin{array}{c}h^{*}{ }_{k}(10) \text { (Sv/Gy) in } \\
\text { absorbed dose }\end{array}$ & $\begin{array}{c}h_{k}^{*}(10)(\mathrm{Sv} / \mathrm{Gy}) \text { in } \\
\text { "kerma approxima- } \\
\text { tion" }\end{array}$ & $\begin{array}{c}h^{*}{ }_{k}(10) \text { (Sv/Gy) in ICRU - 57 } \\
\text { report, Table A.21.pp 179 }\end{array}$ \\
\hline 0.01 & 0.008 & 0.008 & 0.008 \\
\hline 0.02 & 0.607 & 0.608 & 0.61 \\
\hline 0.04 & 1.437 & 1.437 & 1.47 \\
\hline 0.06 & 1.749 & 1.753 & 1.74 \\
\hline 0.08 & 1.747 & 1.745 & 1.72 \\
\hline 0.1 & 1.663 & 1.663 & 1.65 \\
\hline 0.2 & 1.404 & 1.402 & 1.31 \\
\hline 0.3 & 1.300 & 1.300 & 1.26 \\
\hline 0.4 & 1.246 & 1.245 & 1.23 \\
\hline 0.5 & 1.206 & 1.211 & 1.21 \\
\hline 0.6 & 1.186 & 1.188 & 1.17 \\
\hline 0.8 & 1.154 & 1.158 & 1.15 \\
\hline 1 & 1.142 & 1.139 & 1.14 \\
\hline 1.5 & 1.125 & 1.118 & 1.13 \\
\hline 2 & 1.113 & 1.108 & 1.12 \\
\hline 3 & 1.068 & 1.097 & 1.11 \\
\hline 4 & 0.894 & 1.089 & 1.11 \\
\hline 5 & 0.728 & 1.084 & 1.11 \\
\hline 6 & 0.604 & 1.076 & 1.10 \\
\hline 8 & 0.450 & 1.066 & \\
\hline 10 & 0.358 & 1.056 & \\
\hline & & & \\
\hline
\end{tabular}

Table 7. Fluence - air kerma conversion coefficients calculated in "kerma approximation" and in ICRU 57 Report

\begin{tabular}{|c|c|c|c|}
\hline $\begin{array}{c}\text { Energy } \\
(\mathrm{MeV})\end{array}$ & $\begin{array}{c}\text { Mean } k_{\phi} \text { coefficient } \\
\left(\mathrm{pGy} \cdot \mathrm{cm}^{2}\right) \text { this work }\end{array}$ & $\begin{array}{c}k_{\phi} \text { ICRU-57, Table } \\
\text { A.1. pp 159 }\end{array}$ & $\begin{array}{c}k_{\phi} \text { ICRU-57, Table A.21. } \\
\mathrm{pp} \mathrm{179}\end{array}$ \\
\hline 0.01 & 7.595 & 7.43 & 7.60 \\
\hline 0.02 & 1.729 & 1.68 & 1.73 \\
\hline 0.04 & 0.439 & 0.429 & 0.438 \\
\hline 0.06 & 0.293 & 0.289 & 0.292 \\
\hline 0.08 & 0.309 & 0.307 & 0.308 \\
\hline 0.1 & 0.373 & 0.371 & 0.372 \\
\hline 0.2 & 0.857 & 0.856 & 0.856 \\
\hline 0.3 & 1.382 & 1.38 & 1.38 \\
\hline 0.4 & 1.894 & 1.89 & 1.89 \\
\hline 0.5 & 2.383 & 2.38 & 2.38 \\
\hline 0.6 & 2.849 & 2.84 & 2.84 \\
\hline 0.8 & 3.710 & 3.69 & 3.69 \\
\hline 1 & 4.488 & 4.47 & 4.47 \\
\hline 1.5 & 6.154 & 6.14 & 6.12 \\
\hline 2 & 7.563 & 7.55 & 7.51 \\
\hline 3 & 9.967 & 9.96 & 12.0 \\
\hline 4 & 12.137 & 12.1 & 13.9 \\
\hline 5 & 14.176 & 14.4 & 15.8 \\
\hline 6 & 16.183 & 16.1 & 19.5 \\
\hline 8 & 20.126 & 20.1 & 23.2 \\
\hline 10 & 24.123 & 24.0 & \\
\hline & & & \\
\hline
\end{tabular}


Table 8. Air kerma - personal dose equivalent conversion coefficients calculated in absorbed dose, in "kerma approximation" and in ICRU-57 Report

\begin{tabular}{|c|c|c|c|}
\hline $\begin{array}{c}\text { Photon energy } \\
(\mathrm{MeV})\end{array}$ & $\begin{array}{c}h_{k, p}(10)(\mathrm{Sv} / \mathrm{Gy}) \\
\text { in absorbed } \\
\text { dose }\end{array}$ & $\begin{array}{c}h_{k, p}(10) \text { (Sv/Gy) in } \\
\text { "kerma approximation" }\end{array}$ & $\begin{array}{c}h_{k, p}(10) \text { (Sv/Gy) in ICRU - 57 } \\
\text { report, Table A.24.pp 182 }\end{array}$ \\
\hline 0.01 & 0.008 & 0.008 & 0.009 \\
\hline 0.02 & 0.611 & 0.610 & 0.611 \\
\hline 0.04 & 1.504 & 1.501 & 1.490 \\
\hline 0.06 & 1.901 & 1.897 & 1.892 \\
\hline 0.08 & 1.906 & 1.908 & 1.803 \\
\hline 0.1 & 1.814 & 1.812 & 1.492 \\
\hline 0.2 & 1.495 & 1.494 & 1.369 \\
\hline 0.3 & 1.371 & 1.369 & 1.300 \\
\hline 0.4 & 1.304 & 1.301 & 1.256 \\
\hline 0.5 & 1.259 & 1.257 & 1.19 \\
\hline 0.6 & 1.226 & 1.227 & 1.167 \\
\hline 0.8 & 1.188 & 1.188 & 1.139 \\
\hline 1 & 1.169 & 1.166 & 1.117 \\
\hline 1.5 & 1.144 & 1.136 & 1.111 \\
\hline 3 & 1.082 & 1.109 & 1.09 \\
\hline 6 & 0.613 & 1.080 & \\
\hline 10 & 0.364 & 1.059 & \\
\hline
\end{tabular}

Two new sets of conversion coefficients has been calculated replacing total air kerma by collision air kerma for $h^{*}{ }_{k}$ and $h_{k, p}$ (Figures 12 and 13). Looking at these sets of data, the discrepancies with ICRU 57 values do not exist anymore. This leads to the conclusion that the ICRU 57 data set was calculated with the collision air kerma rather than the air kerma, and therefore that the data of table A1 page 59 of ICRU 57 are related to collision air kerma.

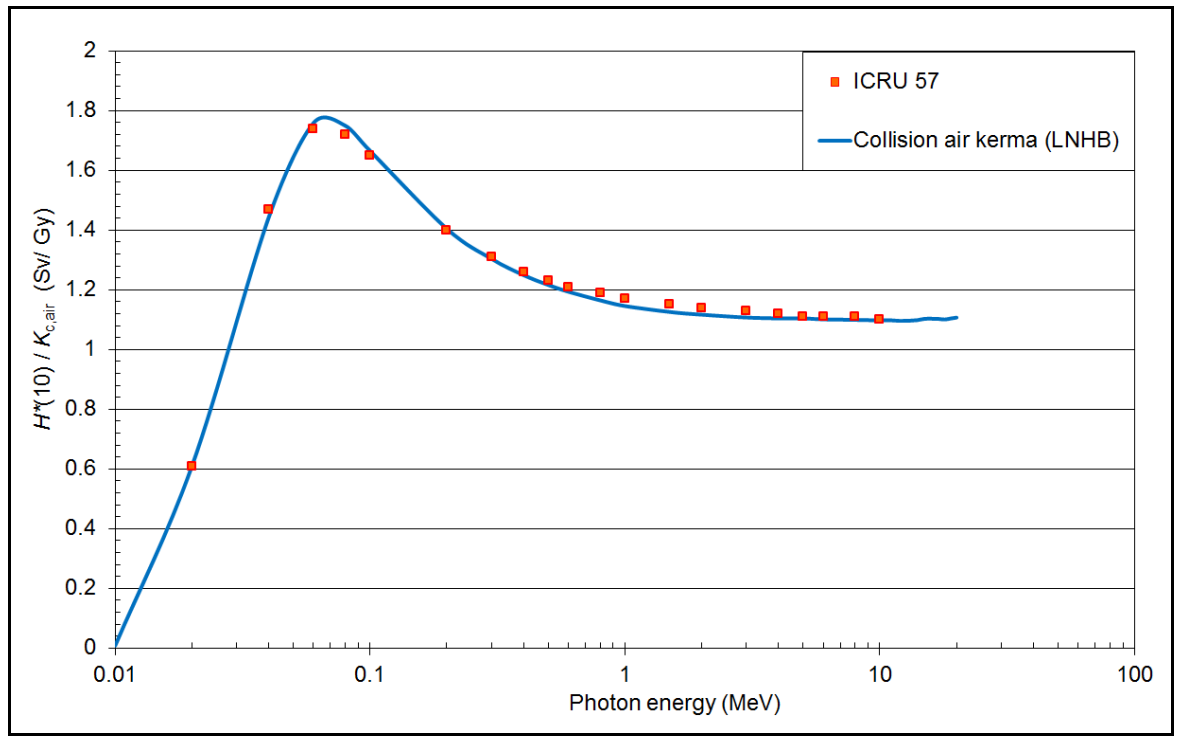

Figure 12. $h^{*}{ }_{k}(10)$ values as function of energy (according to the ICRU-57 Report and using collision air kerma in "kerma approximation") 


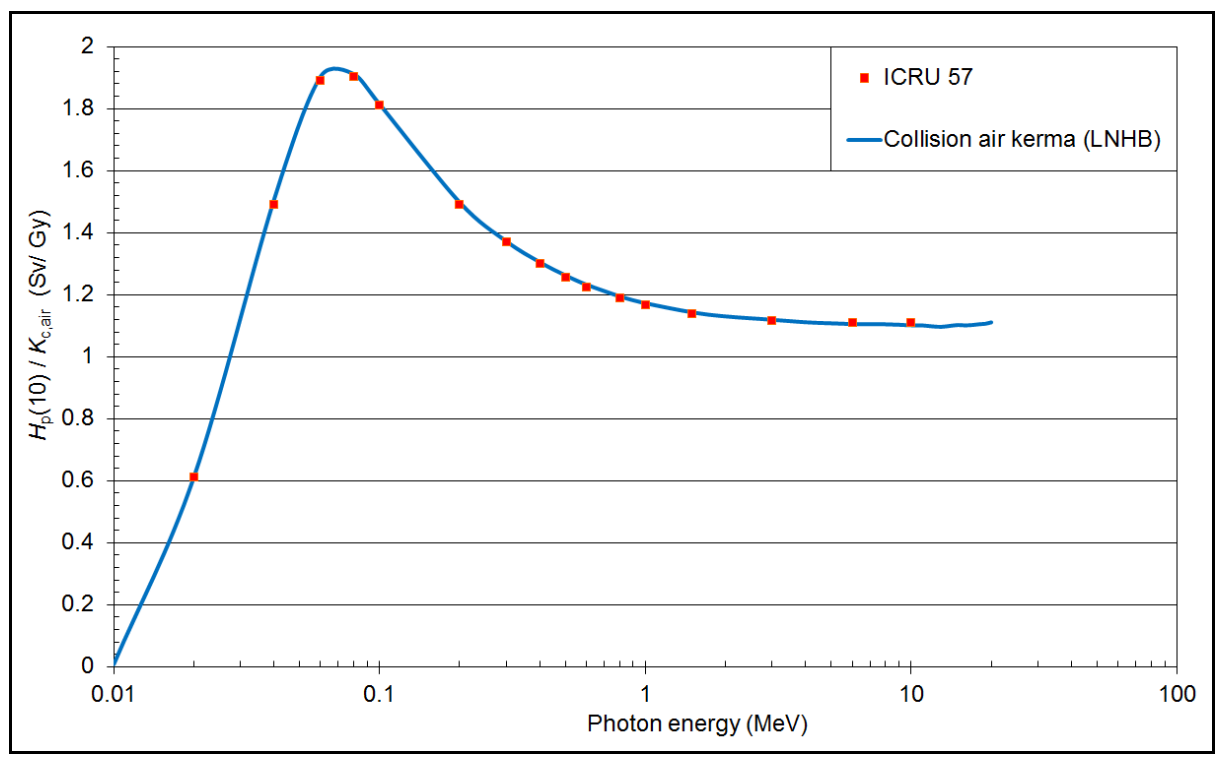

Figure 13. $h_{k, p}(10)$ values as function of energy (according to the ICRU-57 Report and using collision air kerma in "kerma approximation")

The coefficients using collision air kerma are given in Table 9.

Table 9. $h_{k}^{*}(10)$ and $h_{k, p}(10)$ values using collision air kerma

\begin{tabular}{|c|c|c|}
\hline $\begin{array}{l}\text { Photon energy } \\
(\mathrm{MeV})\end{array}$ & $\begin{array}{l}h_{k}^{*}(10) \text { using collision air kerma } \\
\text { (Sv/Gy) }\end{array}$ & $\begin{array}{c}h_{k . p}(10) \text { using collision air kerma } \\
\text { (Sv/Gy) }\end{array}$ \\
\hline 0.01 & 0.008 & 0.008 \\
\hline 0.02 & 0.610 & 0.611 \\
\hline 0.04 & 1.442 & 1.505 \\
\hline 0.06 & 1.759 & 1.905 \\
\hline 0.08 & 1.749 & 1.912 \\
\hline 0.1 & 1.665 & 1.815 \\
\hline 0.2 & 1.405 & 1.498 \\
\hline 0.3 & 1.304 & 1.372 \\
\hline 0.4 & 1.249 & 1.306 \\
\hline 0.5 & 1.216 & 1.263 \\
\hline 0.6 & 1.194 & 1.233 \\
\hline 0.8 & 1.165 & 1.195 \\
\hline 1.0 & 1.146 & 1.173 \\
\hline 1.5 & 1.126 & 1.144 \\
\hline 2 & 1.117 & 1.130 \\
\hline 3 & 1.107 & 1.120 \\
\hline 4 & 1.105 & 1.112 \\
\hline 5 & 1.104 & 1.108 \\
\hline 6 & 1.101 & 1.106 \\
\hline 8 & 1.099 & 1.105 \\
\hline 10 & 1.098 & 1.102 \\
\hline 11 & 1.098 & 1.101 \\
\hline 12 & 1.096 & 1.098 \\
\hline 13 & 1.097 & 1.097 \\
\hline 14 & 1.099 & 1.100 \\
\hline
\end{tabular}


Table 9 continue. $h_{k}^{*}(10)$ and $h_{k, p}(10)$ values using collision air kerma

\begin{tabular}{|l|l|l|}
\hline 15 & 1.103 & 1.103 \\
\hline 16 & 1.103 & 1.101 \\
\hline 17 & 1.103 & 1.103 \\
\hline 18 & 1.101 & 1.105 \\
\hline 19 & 1.104 & 1.107 \\
\hline 20 & 1.107 & 1.111 \\
\hline
\end{tabular}

Finally, the mean CC's over the whole spectrum produced by the LINAC were calculated using two assumptions: the first taking into account the collision air kerma and air kerma approximation as in ICRU 57, and the second accounting for the full transport of secondary particles (therefore in line with the definition of the dose equivalent, that is to say taking into account the energy really absorbed locally). These mean conversion coefficients from $K_{\text {air }}$ to $H^{*}(10)$ and $H_{p}(10)$ for the energy spectrum of the LINAC radiation protection beam are given in Table 10.

Table 10. Mean values of conversion coefficients obtained from mono-energetic conversion coefficients for the radiation protection beam

\begin{tabular}{|c|c|c|}
\hline $\begin{array}{c}\text { Calculation } \\
\text { hypotheses }\end{array}$ & $\begin{array}{c}\text { total tissue kerma and collision air } \\
\text { kerma (according to ICRU-57) } \\
\text { Figures } 12 \text { and } 13\end{array}$ & $\begin{array}{c}\text { absorbed dose in tissue } \\
\text { and total air kerma } \\
\text { Figures 10 and 11 }\end{array}$ \\
\hline$h_{k}^{*}(10)(\mathrm{Sv} / \mathrm{Gy})$ & 1.103 & 0.535 \\
\hline$h_{k, p}(10)(\mathrm{Sv} / \mathrm{Gy})$ & 1.108 & 0.544 \\
\hline
\end{tabular}

These mean coefficients have been compared to mono-energetic conversion coefficients. The values in Table 10 are close to those for a beam of $6 \mathrm{MeV}$, for which we have: $h^{*}{ }_{k}(10)=1.076$ $\mathrm{Sv} / \mathrm{Gy}$ and $h_{k, p}(10)=1.080 \mathrm{~Sv} / \mathrm{Gy}$, confirming our evaluation of the mean equivalent energy of the radiation protection beam. These results validate our choice of the target designed and built for the LINAC, as regards the initial objective, which is to create a radiation protection photon beam with similar characteristics as those of a mono-energetic beam of 6 to $7 \mathrm{MeV}$.

\section{Conclusions}

In this work, a reference high-energy photon beam for radiation protection was designed and produced using a LINAC operated in electron mode and tuned to generate $18 \mathrm{MeV}$ electrons. An additional target/filter was added at the output of the LINAC head. This target/filter is made of a combination of copper and graphite materials, in order to harden the spectrum and decrease the dose equivalent rate. The new radiation field has a mean energy in terms of fluence of $6.17 \mathrm{MeV}$. The kerma rate is homogenous on a $30 \mathrm{~cm} \times 30 \mathrm{~cm}$ area at a distance of $1 \mathrm{~m}$ from the target. A dedicated primary standard based on cavity ionization chamber has been constructed allowing the absolute measurement of the air kerma in the new high-energy photon beam. The measured air kerma rate lies between 0.2 and $0.036 \mathrm{~Gy} / \mathrm{h}$ at $1.45 \mathrm{~m}$ and 3.45 from the target respectively. The standard uncertainty is equal to $2.3 \%$.

Monte Carlo simulations were used to calculate the conversion coefficients from air kerma to dose equivalents quantities above $10 \mathrm{MeV}$ up to $20 \mathrm{MeV}$. The results show a good agreement with the ICRU 57 data taking into account the kerma approximation for the calculations and the collision air kerma rather than the total air kerma. This demonstrates that the conversion coefficients published in ICRU 57 were related to collision air kerma. Using these results the conversion coefficients for the whole LINAC spectrum were calculated. Taking into account that the LINAC produced pulsed radiation, this new radiation field can be used to calibrate any passive dosimeters and ionization chambers. Despite the fact that for Geiger-Muller and proportional counters the instantaneous dose rate is too high, leading to a saturation of detectors, calibrations of passive dosimeters in a high-energy photon beam are now available at LNE-LNHB. 


\section{References.}

1. International Standard ISO 4037-1:1996, ISO 4037-2:1997, ISO 4037-3:1999 „X and gamma reference radiation for calibrating dosemeters and doserate meters and for determining their response as a function of photon energy"

2. Calibration and Measurement Capabilities - Ionizing Radiation. Complete CMCs in Ionizing Radiation for Germany. The BIPM key comparison database, February 2013 http://kcdb.bipm.org/AppendixC/country_list_search_RI.asp?CountSelected=PTB;10;-;6;\&branch=1\&quantity=10\&source=6\&country_sel=DE accessed on April 23, 2014)

3. Calibration and Measurement Capabilities - Ionizing Radiation. Complete CMCs in Ionizing Radiation for Russian Federation. The BIPM key comparison database, July 2004 (http://kcdb.bipm.org/AppendixC/country_list_search_RI.asp?CountSelected=VNIIM;8;-;6;\&branch $=1 \&$ quantity $=8 \&$ source $=6$ accessed on April 23, 2014)

4. F. Delaunay, M. Donois, J. Gouriou, E. Leroy, A. Ostrowsky, „New LNHB primary standard for 60Co air kerma" Metrologia (2010), Vol. 47, pp. 652-658

5. ICRU Report No. 57 „Conversion Coefficients for use in Radiological Protection against External Radiation” (1998)

6. ICRU Report No. 44 „Tissue Substitutes in Radiation Dosimetry and Measurement" (1989)

7. J. Mazurier, Ph. D. Thesis „Adaptation of Monte Carlo code PENELOPE for absorbed dose metrology: characterization of high energy X photon beams and calculation of correction factors of reference dosemeters", 1999

8. D. Dusciac, M. Boudiba, J.-M. Bordy, J. Daures, „Etude pour l'établissement d'une référence de faisceaux photoniques de haute énergie pour la radioprotection", Congrès de la Société Française de Radioprotection (SFRP), Bordeaux, June 2013

9. ICRU Report No. 39 „Determination of Dose Equivalents Resulting from External Radiation Sources" (1985)

10. ICRU Report No. 47 „Measurement of Dose Equivalents from External Photon and Electron Radiations" (1992)

11. J. R. Greening „Fundamentals of Radiation Dosimetry”, Second Edition, CRC Press (1985)

12. X-team 5, MCNP - A General Monte Carlo N-Particle Transport Code, Version5, rapport LAUR-03-1987 (2003)

13. Salvat F., Fernandez-Varea J.-M., Acosta E. et Sempau J., "PENELOPE, A code system for Monte Carlo simulation of electron and photon transport", Proceedings of a Workshop/Training course, OECD/NEA, 5-7 novembre 2001, NEA/NSC/DOC(2001)19, ISBN:92-64-18475-9, http://www.oecdnea.org/tools/abstract/detail/nea-1525/.

14. LLNL Evaluated Photon Data Library (EPDL), UCRL-50400, Vol. 6, Rev. 5 (1997)

15. J. Daures, J. Gouriou, J. M. Bordy, „Monte Carlo determination of the conversion coefficients $\mathrm{Hp}(3) / \mathrm{Ka}$ in a right cylinder phantom with ,PENELOPE' code. Comparison with ,MCNP' simulations" Radiation Protection Dosimetry (2011), Vol. 144, No. 1-4, pp. 37-42 